\title{
Restoring a Smile Post Covid-19 Associated Mucormycosis: A Case Report
}

\author{
Janardhan Garde ${ }^{1}$, Aliya Khan², Sharayu Dhande ${ }^{3 *}$, Dhriti Garde ${ }^{4}$ and \\ Sangeeta Muglikar ${ }^{5}$ \\ ${ }^{1}$ Department of Oral and Maxillofacial Surgery, M A Rangoonwala College of Dental Sciences \\ and Research Centre, India \\ ${ }^{2}$ Private Practitioner, India \\ Case Report \\ Volume 6 Issue 4 \\ Received Date: June 21, 2021 \\ Published Date: October 18, 2021 \\ DOI: $10.23880 /$ oajds-16000314
}

${ }^{3}$ Department of Periodontology and Oral Implantology, M A Rangoonwala College of Dental

Sciences and Research Centre, India

${ }^{4}$ Final Year, BDS Student, Bharti Vidyapeeth Dental College and Hospital, India

${ }^{5}$ Department of Periodontology and Oral Implantology, M A Rangoonwala College of Dental Sciences and Research Centre, India

*Corresponding author: Sharayu Dhande, Department of Periodontology and Oral Implantology, M A Rangoonwala College of Dental Sciences and Research Centre, Azam Campus, Pune-411001, India, Email: dhandesharn1234@gmail.com

\section{Abstract}

Oral health is influenced by a variety of local and systemic factors. Oral cavity is exposed to a variety of viruses, bacteria and fungi. SARS-CoV-2 caused Corona virus disease (COVID) predisposes the affected individuals to immunocompromised state, thereby increasing the risk of other infections. Mucormycosis is now-a-days most commonly encountered fungal infection in the post COVID era. Diagnosis of such aggressive infections is based on co-relation of clinical signs and symptoms and radiographic features with histopathological diagnosis. Surgical debridement of the affected area is the first line of treatment. Prosthetic rehabilitation of the surgically resected area is the next step in the treatment of such fulminant infections in order to help restore form and function for the affected individual. The present case report focusses on treating this life-threatening fungal infection by surgical debridement with adjunctive anti-fungal therapy and prosthetic rehabilitation in a mucormycosis affected patient in order to restore form and function.

Keywords: Mucormycosis; COVID-19; Bilateral Subtotal Maxillectomy; Immunocompromised Host; Prosthetic Rehabilitation

Abbreviations: COVID: Corona Virus Disease; AIDS: Acquired Immune Deficiency Syndrome.

\section{Introduction}

COVID-19 is an abbreviation for Corona virus disease 2019 which is an infectious viral disease caused by Severe Acute Respiratory Syndrome Coronavirus-2 (SARS-CoV-2). It was first isolated from three people with pneumonia in Wuhan and was later declared as global pandemic in December 2019 [1,2]. Common symptoms at onset of illness were fever, cough, and myalgia; less common symptoms were sputum production, headache, haemoptysis, and diarrhoea, dyspnoea, lymphopenia, abnormal findings on chest CT $[3,4]$. Complications included acute respiratory distress syndrome, RNAaemia, acute cardiac injury and secondary infections, higher plasma levels of IL-2, IL-7, IL-10, GSCF, IP-10, MCP-1, MIP-1A, and TNF- $\alpha$ [5]. The standard method of diagnosis is by real time reverse transcriptase polymerase chain reaction (rRT-PCR) from a nasopharyngeal swab. Virus-specific nucleic acid sequences were detected in lung fluid, blood and throat swabs [6]. 
Paultauf in 1885 first described "Mucormycosis" [7,8]. Inhalation of fungal spores of Mucorales fungus cause the fungal infection named "Mucormycosis" $[9,10]$. It is regarded as third most common angio-invasive fungal infection after Candidiasis and Aspergillosis [11]. The fungus is known to rapidly proliferate in immunocompromised host, the altered immunity in such individuals results in rapid proliferation and invasion of fungus in to the deeper tissues $[12,13]$.

Certain pre-disposing factors for mucormycosis are uncontrolled diabetes mellitus, few malignancies such as leukemias and lymphomas, neutropenia, renal failure, organ transplantion, long-term corticosteroid therapy, patients on immunosuppressive therapy, liver cirrhosis, burns, proteinenergy malnutrition, along with acquired immune deficiency syndrome (AIDS) affected individuals possess more risk for this fatal infection [14].

Once infected progression of fungus is rapid enough to invade arteries, formation of intra-luminal mucor thrombi within the blood vessels results into necrosis of underlying hard and softtissues [15-18]. The spread through the arteries is rapid enough to reach orbital region, para-nasal sinuses and other intra-cranial structures $[19,20]$.

Stringent management of this infection with proper surgical debridement is the key to treat this fatal infection and thereby reduce morbidity and mortality associated with this infection [21]. We report a case of Post-COVID-19 Mucormycosis treated with surgical debridement followed by prosthetic rehabilitation.

\section{Case Presentation}

A 55 year old female patient reported to the Department of Oral and Maxillofacial Surgery with a chief complaint of pain, numbness with swelling on left side of face since 45 days along with associated mobility of teeth present in upper left posterior region. Neither any relevant family history was noted nor any previous systemic illness was reported. On general examination vital signs were found normal. Informed consent was taken before initiating the treatment and also the treatment plan was explained to the patient.

Patient was tested COVID-19 positive about 4 months ago for which she was treated with medications by her family physician. Her HRCT score was 6/25 at that time and was neither hospitalised nor given any steroids for the same.

Patient was apparently asymptomatic 3 months back, she then subsequently developed pain in the upper right and left posterior region for which she was treated with medication by a local dentist. About 2 months ago, she then experienced sharp shooting type of pain and swelling in left posterior region of upper jaw and blocked left nostril for which, functional endoscopic sinus surgery was performed in order to assess total number of sinuses involved.

Extraoral examination revealed a mild diffuse swelling over the left side of the middle third of the face seen extending mediolaterally from lateral aspect of nose to the outer canthus of the eye and superior-inferiorly from the infraorbital region to $1 \mathrm{~cm}$ above the corner of the mouth, respectively. On palpation, the swelling was soft in consistency, tender without local rise of temperature. No nasal twang of voice experienced. Paresthesia over left side of infra-orbital region was reported with circumorbital edema over left eye. Eye and pupillary movements were normal. Facial expressions were normal. The submandibular, sublingual, cervical and preauricular lymphnodes were not palpable. Eye and pupillary movements were normal. Circum-orbital edema not noted (Figure 1).

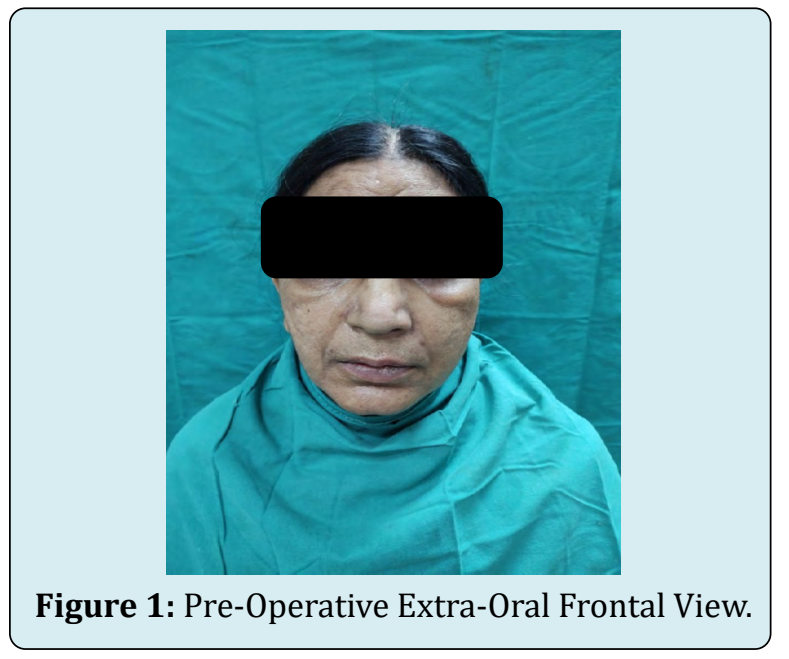

Intraoral examination revealed draining sinus in the upper front region of jaw extending from mesial aspect of right first pre-molar to distal aspect of left molar. Grade II mobility was present with $11,12,13,14,21,22,23,24,25$. The soft tissue assessment of upper anterior and posterior region revealed gingiva in soft and edematous consistency (Figures 2-5).

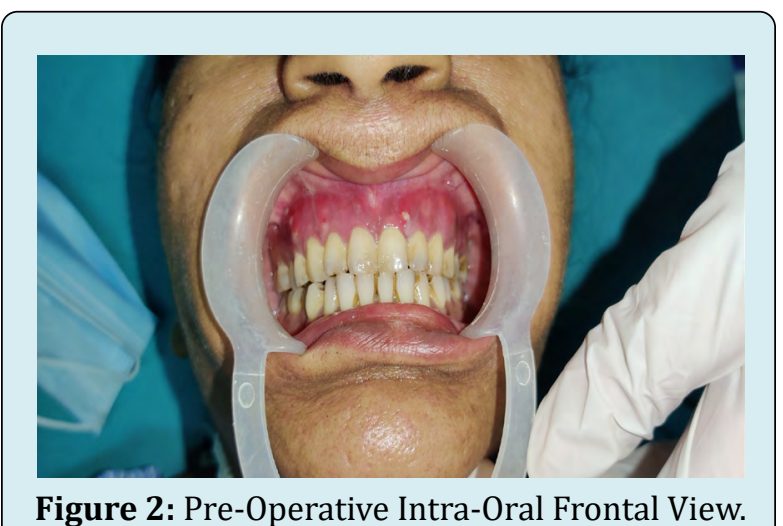

Figure 2: Pre-Operative Intra-Oral Frontal View. 


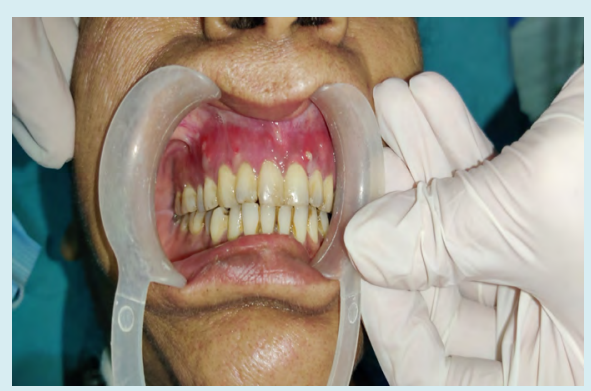

Figure 3: Right Side Pre-Operative Intra-Oral View.

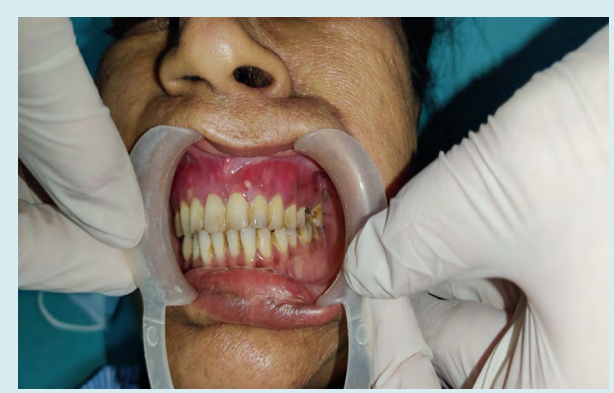

Figure 4: Left Side Pre-Operative Intra-Oral View.

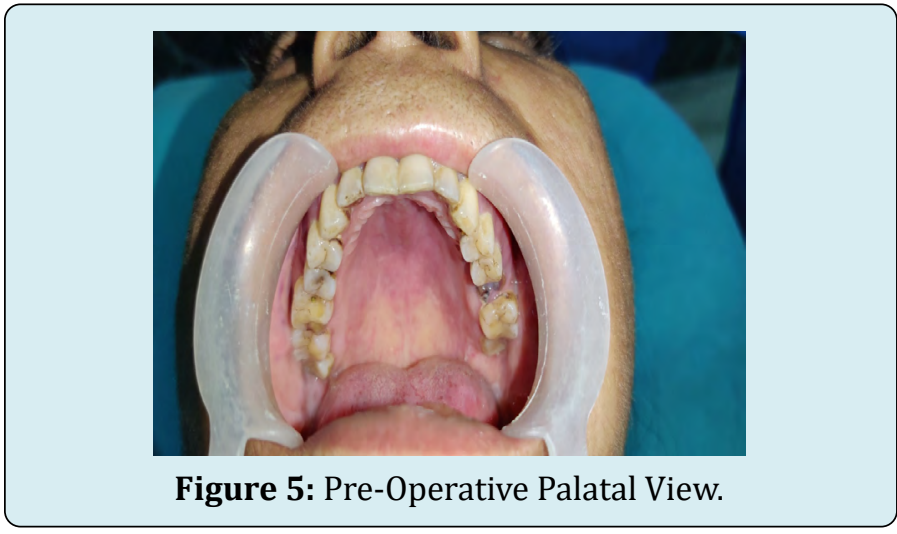

In surgical phase, Bilateral Subtotal Maxillectomy was performed and wide local excision of mucormycosis was carried out. Orbital floor reconstruction along with palatal floor was carried out (Figures 6 \& 7).

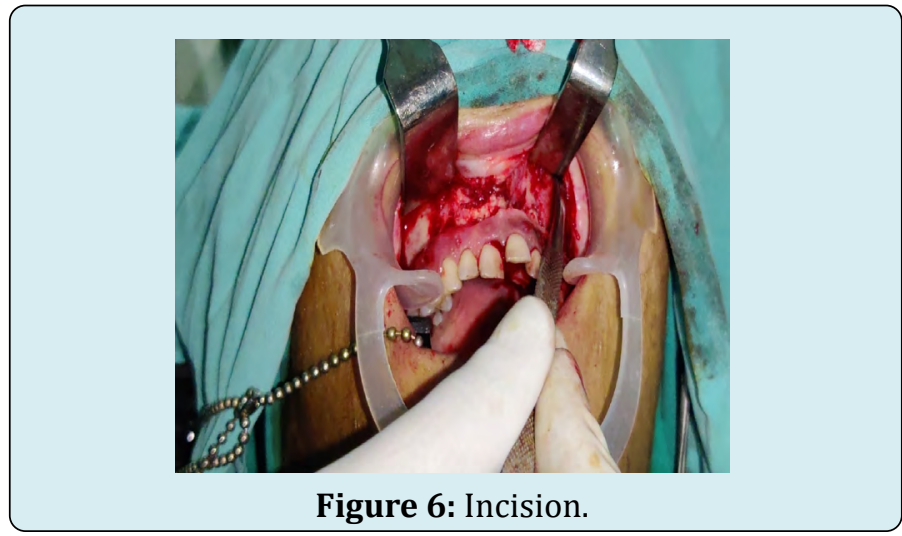

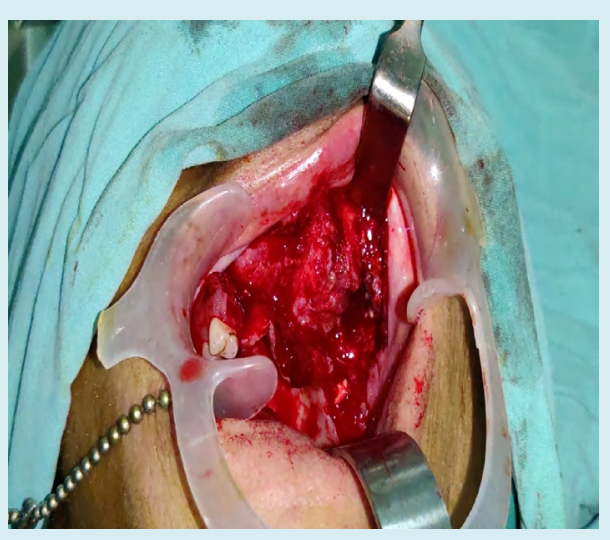

Figure 7: Surgical Debridement.

The excised tissue comprised of a segment of right maxilla with 5 intact teeth measuring $5 \times 2.5 \times 2.5 \mathrm{~cm}$ in size. 6 teeth along with few bony spicules were lying separately (Figures $8 \& 9$ ). Floor of maxillary sinus shows granular soft white mucosa. Multiple soft and bony pieces of $2 \times 2 \mathrm{~cm}$ in size of right sinus mucosa, two soft tissue pieces together $2 \times 1 \mathrm{~cm}$ in size of left sinus mucosa were further sent in $10 \%$ formalin for histopathological examination. Tissue lining was sent in saline only for fungal staining $(\mathrm{KOH})$ examination.

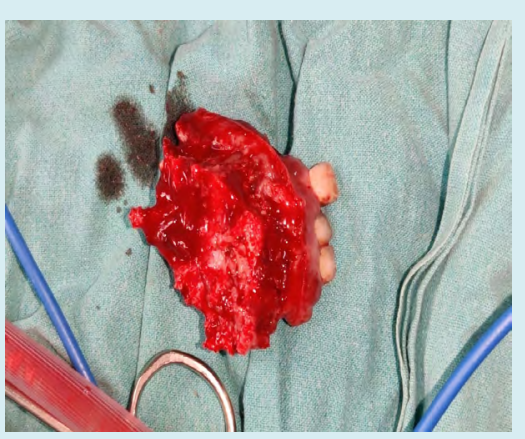

Figure 8: Resected Maxilla Superiorly.

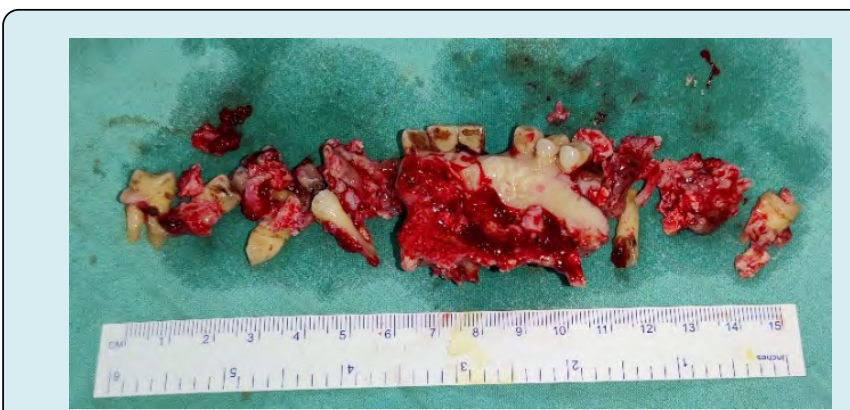

Figure 9: Resected Maxilla Inferiorly with Extracted Teeth.

Surgical site was sutured with 3-0 vicryl sutures (Figure 10) Roller gauze soaked in Amphotericin $B$ gel was placed in the excise part of maxilla. Roller gauze dressing was changed 
after 2 days and through betadine irrigation was done.

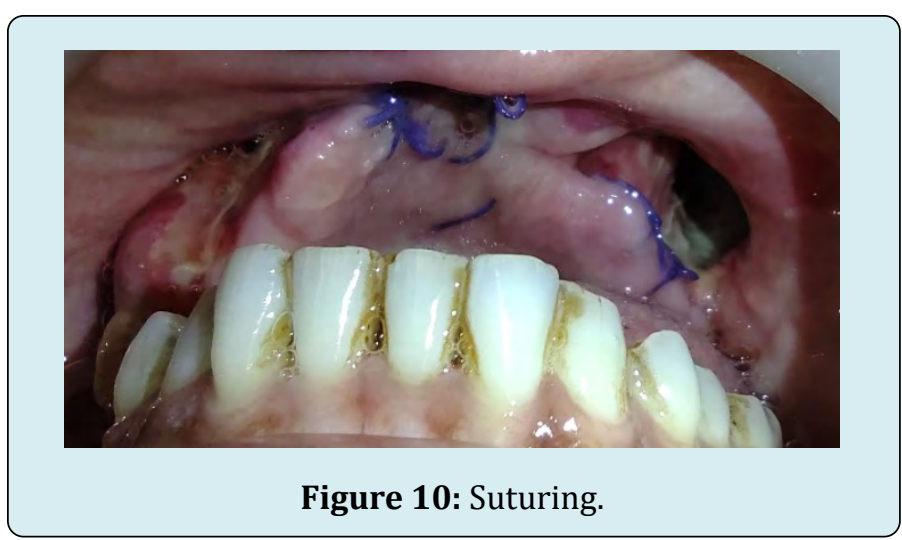

\section{Post-Operative Care Includes}

Patient was kept on RT feed until obturator was placed. Regular dressing of patient was carried out. Patient was administered liposomal Amphotericin B injection for 11 days. Regular dressing was done after discharge as well for 2 months. Patient was advised Tablet Posaconazole (300 mg) OD for 3 months. 15 days after the surgery the procedure for
Prosthetic Rehabilitation was initiated and within 10 days an obturator along with replacement of missing teeth (acrylic teeth) was prepared, so as to restore the form and function.

Provisional Diagnosis: Post- COVID-19 Mucormycosis Differential Diagnosis: Deep fungal infections, squamous cell carcinoma, chronic granulomatous infection.

\section{Radiographic Diagnosis}

- CT-PNS: Revealed complete opacification of the left maxillary sinus. Mild mucosal thickening of right maxillary, left ethmoid and right sphenoidal sinuses was noted. The Final CT-PNS diagnosis is Invasive Fungal Sinusitis (Figure 11).

- MRI-PNS: Reveals mucosal thickening involving bilateral maxillary sinus, left ethmoid and sphenoid sinus. The final diagnosis is Invasive Fungal Sinusitis with Left Premaxillary and left masticator space (Figure 12-17).

- Fungal Staining: Right side - Broad, aseptate, ribbonshaped hyaline fungal hyphae seen. Left side - No fungal element noted after 7 days culture at $37^{\circ}$ and room temperature (Figure 18).

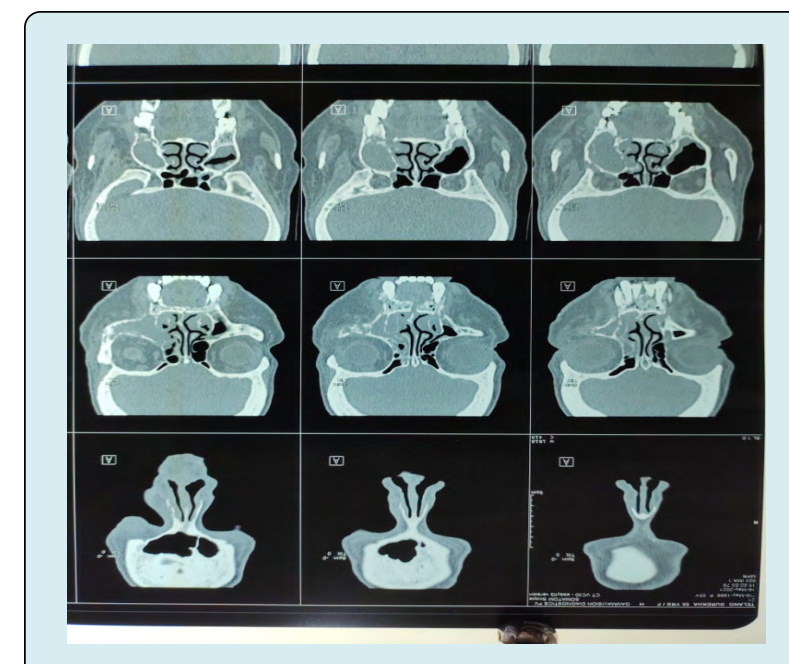

Figure 11: Pre-Operative CT-PNS Images.

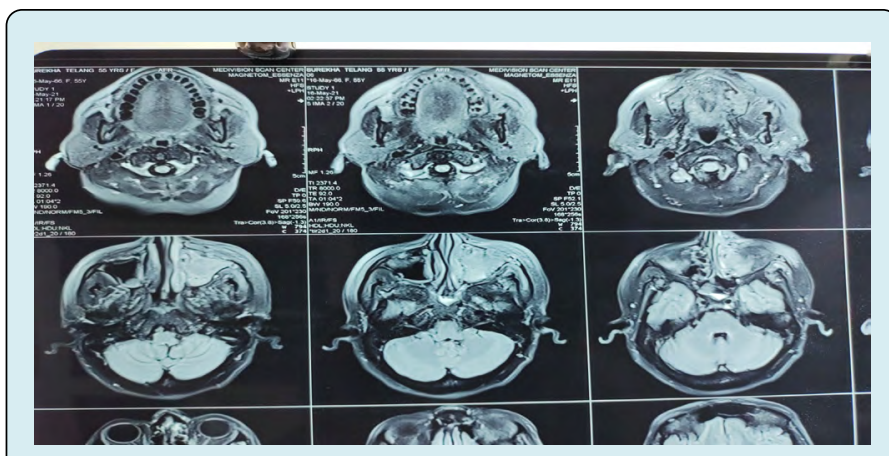

Figure 12: Pre-Operative MRI Images. 


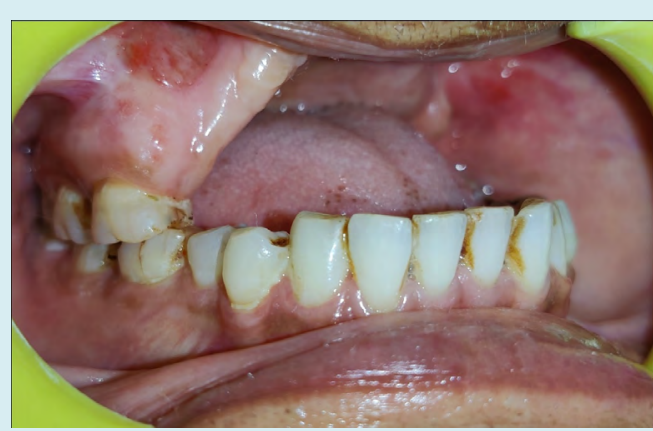

Figure 13: Post-Operative Follow-Up 1 Month.

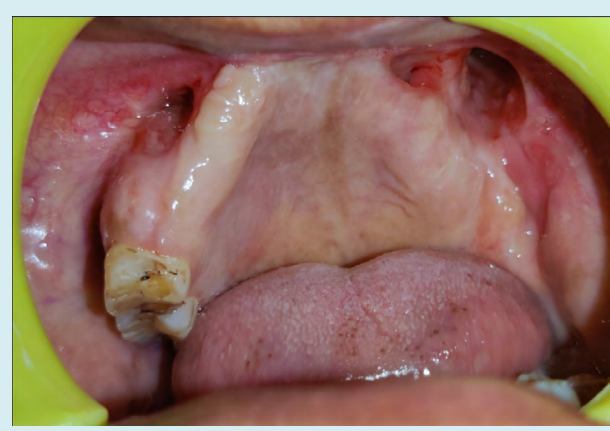

Figure 14: Post-Operative Follow-Up 8 Months.

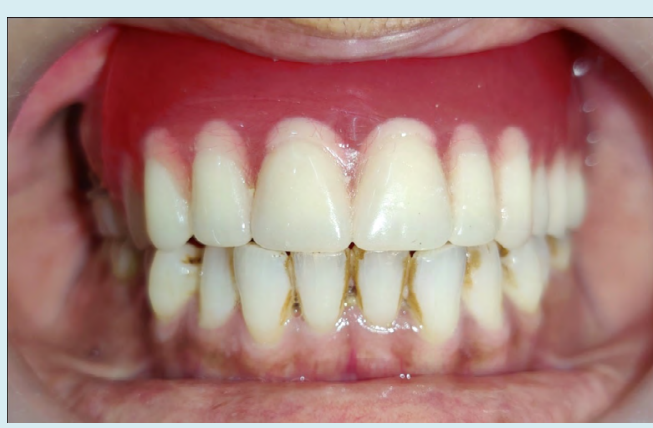

Figure 15: Prosthetic Rehabilitation-Frontal View.
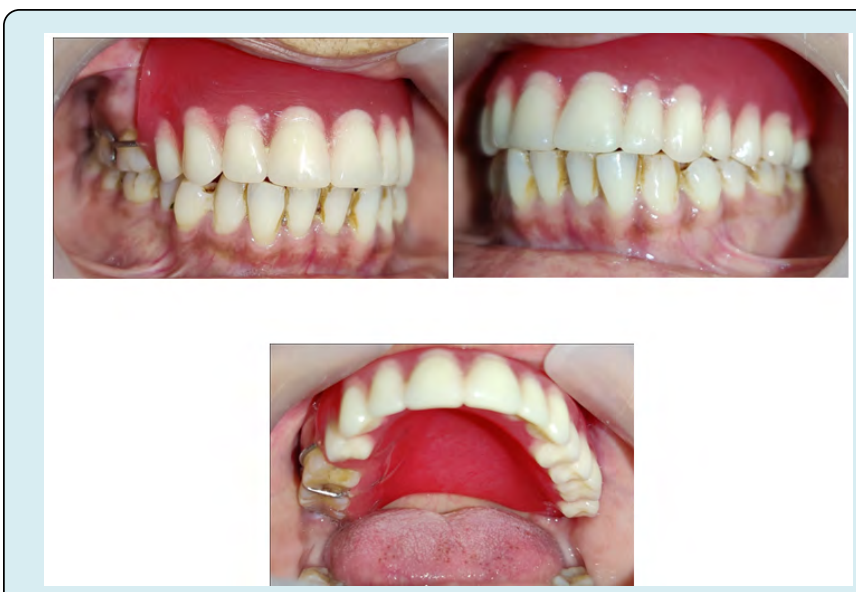

Figure 16: Prosthetic Rehabilitation Lateral View.

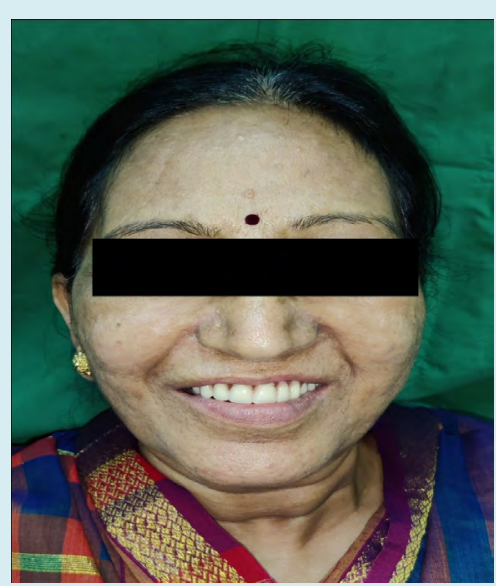

Figure 17: Post-Operative Extra-Oral View.

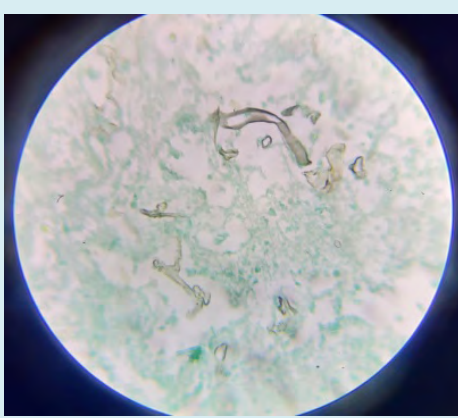

Figure 18: Fungal Staining (Right side).

\section{Histopathology}

The excised tissue was sent for histopathological examination in 3 sections: Bilateral subtotal maxillectomy, right sinus mucosa, left sinus mucosa (Figure 19).

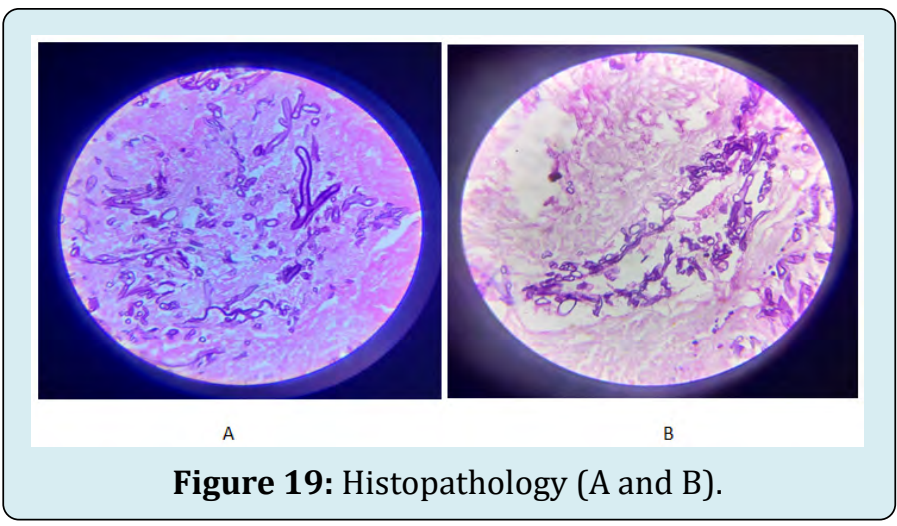

Histopathology of Bilateral Subtotal Maxillectomy: Moderate mixed inflammation in maxillary sinus mucosal tissue with foreign body giant cell reaction and occasional histiocytic granulomas. Mucosal tissue was viable with absence of fungal hyphae. Few sections from maxillary 


\section{Open Access Journal of Dental Sciences}

bone show bony trabeculae separated by fatty marrow spaces showing chronic inflammation with granulomas with multiple broad, aseptate, ribbon-like fungal hyphae branching at right angles. Angioinvasion noted. PAS stain highlights fungal morphology.

\section{Histopathology of Right Sinus and Left Sinus Mucosa: Sections show sinus mucosa with dense chronic inflammatory granulation tissue with multiple histiocytic fungal granulomas bordered by multinucleate histiocytic and foreign body giant cells. Occasional fungal hyphae seen. No atypia or malignancy noted.}

Final Diagnosis: Post COVID-19 Mucormycosis.

\section{Discussion}

In the present case report of mucormycosis, bilateral subtotal maxillectomy with wide local excision of necrosed area was carried out. Stringent debridement of the affected area was carried out in order to reduce chances of recurrence.

Mucormycosis of oral cavity could be due to dissemination of infection from nose, the infection may result in to palatal ulceration leading to necrosis and discoloration of the affected area. Secondly, if the infection is through direct contamination of wound, clinical findings may appear anywhere within the oral cavity. Cavernous sinus thrombosis could be a serious complication noted with mucormycosis of maxilla [22]. Another significant factor in growth of mucormycosis fungus is the iron metabolism. Iron is known to bind with fungal hyphae and result in production of 'rhizoferrin'. This rhizoferrin complex is then taken up by fungus and thus helps in its vital functions [23-25].

Multiple reconstructive options are available for reconstruction of maxillofacial defects. Factors determining the selection of reconstruction of defect are dimensions of the defect, presence of infra-orbital rim, extent of the palatal involvement, underlying skin, esthetic considerations of patients. In the present case report, palatal and orbital floor reconstruction was carried out post-surgical debridement to seal the oro-antral communication. Regardless of the method used for orbital reconstruction, accurate replacement of the bony orbit is important factor to prevent complications such as orbital dystopia, exophthalmos and enophthalmos. In the present case, during the orbital reconstruction, the contralateral eye was draped appropriately if the globe and rim are placed symmetrically, also palpate to ensure that there was no excessive pressure on the globe. Following orbital floor reconstruction, patient was constantly monitored for changes in her vision. Peri-orbital skin was assessed for scarring.
Another significant part of this case was palatal floor reconstruction which is an essential factor for prosthetic rehabilitation. The main goal of prosthetic rehabilitation is to restore the partition between nasal and oral cavity, restore palatal contours, replace missing dentition, provision for retention, stability, support for the prosthesis without compromising the residual dentition and supporting structures. In the present case, along with orbital and palatal floor reconstruction, all the missing teeth were replaced with help of an obturator. Patient was assessed for follow-up at 1 month and at 8 months (Figures 13-17)

Mani, et al. carried out bilateral maxillectomy to treat mucormycosis. Prosthetic rehabilitation of the same was carried out using fabrication of complete hollow obturator. This new design of hollow obturator has certain advantages like light in weight, enhancement in retention with restoring form and function for the patient over the conventional obturator design. Thus, authors conclude that this modification in obturator will help patients improve their speech and mastication abilities compared to the conventional obturator [26]

Gowda, et al. carried out a case study in which they used a combination prosthesis to rehabilitate residual maxillary and orbital defects secondary to surgical management of sino-orbital mucormycosis. The prosthesis comprised of obturator and orbital reconstruction part in a single design with help of innovative method of achieving retention in order to provide complete functional and esthetic rehabilitation of the patient. Thus, authors concluded that a combination prosthesis could serve as a better option in treatment of such defects. [27].

Gaur, et al. treated a case of rhino-orbital-cerebral mucormycosis with a implant-supported maxillofacial prosthesis with zygomatic and pterygoid implants by following an immediate loading protocol. The authors concluded that implant supported prosthetic rehabilitation could be a better option for rehabilitation of patients whilst a conventional obturator [28].

\section{Conclusion}

Mucormycosis is a angio-invasive fungal infection requiring an alarming and prompt therapeutic approach for its management. Surgical debridement of the necrosed area with appropriate anti-fungal therapy remains gold standard in treatment of such fulminant infections. In the present case report, bilateral subtotal maxillectomy with orbital and palatal floor reconstruction was carried out with proper debridement of the affected area in order to reduce the chances of the recurrence. 


\section{Conflict of Interest: None.}

\section{References}

1. Di Gennaro F, Pizzol D, Marotta C, Antunes M, Racalbuto V, et al. (2020) Coronavirus diseases (COVID-19) current status and future perspectives: a narrative review. Int J Environ Res Public Health. 17(8): 2690.

2. Kumar D, Malviya R, Sharma PK (2020) Corona virus: a review of COVID-19. EJMO 4(1): 8-25.

3. Hsu LY, Chia PY, Lim JF (2020) The Novel Coronavirus (SARS-CoV-2) Epidemic. Ann Acad Med Singap 49(105): 105-107.

4. Yin Y, Wunderink RG (2018) MERS, SARS and other coronaviruses as causes of pneumonia. Respirology 23(2): 130-137.

5. Huang C, Wang Y, Li X, Ren L, Zhao J, et al. (2020) Clinical features of patients infected with 2019 novel coronavirus in Wuhan, China. The lancet 395(10223): 497-506.

6. Lu H, Stratton CW, Tang YW (2020) Outbreak of pneumonia of unknown etiology in Wuhan, China: the mystery and the miracle. J Med Virol 92(4): 401-402.

7. Paulltauf A (1885) Mycosis mucorina. Virchows Arch Pathol Anat 102: 543-564.

8. Viterbo S, Fasolis M, Garzino Demo P, Griffa A, Boffano P, et al. (2011) Management and outcomes of three cases of rhinocerebral mucormycosis. Oral Surg Oral Med Oral Pathol Oral Radiol Endod 112(6): 69-74.

9. Hibbett DS, Binder M, Bischoff JF, Blackwell M, Cannon PF, et al. (2007) A higher-level phylogenetic classification of the Fungi. Mycol Res 111(5): 509-547.

10. Ribes JA, Vanover Sams CL, Baker DJ (2000) Zygomycetes in human disease. Clin Microbiol Rev 13(2): 236-301.

11. Torres Narbona M, Guinea J, Muñoz P, Bouza E (2007) Zygomycetes and zygomycosis in the new era of antifungal therapies. Rev Esp Quimioter 20(4): 375-386.

12. Goel S, Palaskar S, Shetty VP, Bhushan A (2009) Rhinomaxillary mucormycosis with cerebral extension. J Oral Maxillofac Pathol 13(1): 14-17.

13. Salisbury PL, Caloss R, Cruz JM, Powell BL, Cole R, et al. (1997) Mucormycosis of the mandible after dental extractions in a patient with acute myelogenous leukemia. Oral Surg Oral Med Oral Pathol Oral Radiol Endod 83(3): 340-344.
14. Neville WB, Damm D, Allen CM, Bouquot JE (2001) $2^{\text {nd }}$ (Edn.), Philadelphia: W.B.: Saunders, Text Book of Oral \& Maxillofacial Pathology, pp: 16.

15. Leitner C, Hoffmann J, Zerfowski M, Reinert S (2003) Mucormycosis: necrotizing soft tissue lesion of the face. J Oral Maxillofac Surg 61(11): 1354-1348.

16. Pogrel MA, Miller CE (2003) A case of maxillary necrosis. J Oral Maxillofac Surg 61(4): 489-493.

17. Napoli JA, Donegan JO (1991) Aspergillosis and necrosis of maxilla: a case report. J Oral Maxillofac Surg 49(5): 532-534.

18. Brown OE, Finn R (1986) Mucormycosis of the mandible. J Oral Maxillofac Surg 44(2): 132-136.

19. Zapico ADV, Suarez AR, Encinas PM, Angulo CM, Pozuelo EC (1996) Mucormycosis of the sphenoidal sinus in an otherwise healthy patient. Case report and literature review. J Laryngol Otol 110(5): 471-473.

20. Jones AC, Bentsen TY, Fredman PD (1993) Mucormycosis of the oral cavity. Oral Surg Oral Med Oral Pathol 75((4): $455-460$.

21. Bakathir AA (2006) Mucormycosis of the jaw after dental extractions: Two case reports. Sultan Qaboos Univ Med J 6(2): 77-82.

22. Lador N, Polacheck I, Gural A, Sanatski E, Garfunkel A (2006) A trifungal infection of the mandible: Case report and literature review. Oral Surg Oral Med Oral Pathol Oral Radiol Endod 101(4): 451-456.

23. Mathebula SD (2008) Mucormycosis. S Afr Optom 67(1): 36-41.

24. Howard DH (1999) Acquisition, transport, and storage of iron by pathogenic fungi. Clin Microbiol Rev 12(3): 394-404.

25. Ibrahim AS, Spellberg B, Edwards J (2008) Iron acquisition: a novel perspective on mucormycosis pathogenesis and treatment. Curr Opin Infect Dis 21(6): 620-625.

26. Mani UM, Mohamed K, Krishna Kumar A, Inbarajan A (2019) A modified technique to fabricate a complete hollow obturator for bilateral maxillectomy in a patient with mucormycosis-A technical case report. Special Care in Dentistry 39(6): 610-616.

27. Gowda M, Shashidhar MP, Prakash P, Sahoo NK (2021) Rehabilitation of a defect secondary to sino-orbital mucormycosis-A prosthodontic challenge. IP Annals of 


\section{Open Access Journal of Dental Sciences}

Prosthodontics and Restorative Dentistry 7(1): 41-45.

28. Gaur V, Patel K, Palka L (2021) An implant-supported prosthetic rehabilitation of a patient with a bilateral subtotal maxillectomy defect secondary to rhino-orbitalcerebral mucormycosis: A clinical report of a graftless approach. J Prosthet Dent. 